\title{
Performance of Angstrom Model under Algerian Climate
}

\author{
Anouar Bella Baci ${ }^{1,2^{*}}$, Mohamed Salmi ${ }^{1,2}$, Abdelkader Hima ${ }^{3}$, Younes Menni ${ }^{4}$ \\ ${ }^{1}$ Department of Physics, University of M'sila, B.P. 1713, M'sila, 28000, Algeria \\ ${ }^{2}$ Laboratory of Physics and chemistry of Materials, University of M'sila, M'sila, 28000, Algeria \\ ${ }^{3}$ Faculty of Technology, University of El-Oued, El-Oued 39000, Algeria \\ ${ }^{4}$ Unit of Research on Materials and Renewable Energies, Abou Bekr Belkaid University, B.P. 119, Tlemcen 13000, Algeria
}

Corresponding Author Email: anouar.bellabaci@univ-msila.dz

https://doi.org/10.18280/mmep.070111

Received: 18 July 2019

Accepted: 25 January 2020

\section{Keywords:}

solar irradiation measurements, solar irradiation modelling, solar energy, Algerian climate, angstrom model

\begin{abstract}
This study was conducted to estimate the monthly global solar irradiation in the Algerian territory using the Angström model, for seven sites in Algeria, namely: Algiers, Ain Bessem, Constantine, Oran, Djelfa, Mascara and Tamanrasset. The models are based on global solar irradiation in the horizontal surface as well as sunshine hours. To evaluate the results obtained by the different sites we calculated the following relative average algebraic differences: MAE, MBE and RMSE. The results show a remarkable agreement between the measured and computed values, especially in Tamanrasset site where the slope is in the order of 1 . Obtained estimates can be generalized on the whole Algerian territory to provide ease way for researchers to get solar irradiation. However, optimization efforts have to be made to reduce mean error. Future works can be made based on our estimates to study effect of temperature and climatic parameters on the model. This work aim is achieved providing a data generator (software).
\end{abstract}

\section{INTRODUCTION}

The amount of solar irradiation received throughout the Algerian territory exceeds 2000 hours per year [1], which represents a high average compared to the countries of the world [2, 3].

To exploit this energy as a source of photovoltaic systems or thermal photos [4-7], it is necessary to know the quantity of the solar irradiation received by the different regions of the Algerian territory. The best source of this information is the data measured using the pyranometer.

The lack of means of measurement, the unavailability of meteorological stations all over and the surface area of the studied regions, all these present difficulties that obliged the researchers in the different countries of the world to develop models aiming to estimate global solar irradiation at any site. In this work the model is presented based on the linear Angström equation. Other investigations can be found in the referenced papers [8-38] for various solar irradiation models.

Through this recent study, a novel model has been established in order to estimate global solar irradiation from sunshine hours for seven Algerian locations. This model is based on the well-known Angstrom-Prescott linear regression. Statistical analysis of the results was performed using the root mean square error (RMSE), the mean bias error (MBE) and the mean absolute error (MAE) criteria.

The present paper is organized into three sections, the first describing used methods, the second gives information on studied sites and the third contains different obtained results a discussion.

\section{STATISTICAL METHODS}

In this work, we are interested in these methods. They have been used for the development of solar irradiation estimation models in Algeria. This method uses statistical relationships between solar irradiation and insolation [10-13], we present a review of different models used.

\subsection{Linear relationships}

Linear relationship between daily and monthly solar irradiation with sunstroke are considered the simplest and best models for estimating solar irradiation on a horizontal plane in sites where measuring stations are available, they can be applied in sites with the same climate and measured values are unavailable.

The constants of these mathematical relations are coefficients, which are based on the climate of the studied area; they are well represented by the Angström model.

\subsection{Applied model}

For the evaluation of the global solar irradiation on the chosen sites in our work, we chose the Angström model.

Angström model [14]: is the first model used, it is given by the relation (1):

$$
\frac{G}{G_{0}}=a+b\left(\frac{S}{S_{0}}\right)
$$

$\mathrm{G}_{0}$ is calculated using Eq. (2) [15]: 


$$
G_{0}=\frac{24}{\pi} I_{0}\left(1+0.033 \cos \frac{360 n}{365}\right) \times\left(\cos \lambda \cos \delta \sin \omega+\frac{2 \pi}{360} w \sin \lambda \sin \delta\right)
$$

where,

$\mathrm{G}$ is the average monthly global irradiation measured on a horizontal plane $\left(\mathrm{MJ} \cdot \mathrm{m}^{-2} \mathrm{j}^{-1}\right)$,

$\mathrm{G}_{0}$ is the monthly average global irradiation outside the atmosphere on a horizontal plane (MJ.m $\left.\mathrm{m}^{-2} \cdot \mathrm{j}^{-1}\right)$,

$\mathrm{I}_{0}$ is the solar constant, is equal to $1367 \mathrm{Wm}^{-2}$,

$\lambda$ is the latitude of the place,

$w$ is the hour angle, and

$\delta$ is the declination, it is given by Eq. (3) [16]:

$$
\delta=23.45\left[\sin \frac{360(284+n)}{365}\right]
$$

and $\omega$ is the sunset hour angle, defined as

$$
\omega=\cos ^{-1}(-\tan \lambda \tan \delta)
$$

$\mathrm{n}$ represents the number of the day of the year from the first of January, S represents the duration of the effective sunshine, $\mathrm{S}_{0}$ represents the maximum duration of sunshine or duration of the day, its expression is given by Eq. (5) [17-19]:

$$
S_{\mathrm{o}}=\frac{2}{15} \omega
$$

\subsection{Statistical indicators statistical indicators}

To determine the constants $a$ and $\mathrm{b}$ of Equation (1), we calculated the rate $\left(\mathrm{G} / \mathrm{G}_{0}\right)$ and $\left(\mathrm{S} / \mathrm{S}_{0}\right)$ for each day and month for the different sites. To evaluate the results obtained by the different models, we calculated the following relative average algebraic differences:

- MAE (Mean Absolute Error): measures the average magnitude of errors in a series of forecasts, regardless of direction. It measures precision for continuous variables, its expression is given by Eq. (6) [20]:

$$
M A E=\sum_{1}^{N}\left|G_{i, m}-G_{i, c}\right| / N
$$

- MBE (Mean Bias Error): provides information on the long-term performance of expressions, offering information regarding more or underestimation of estimated data, given by Eq. (7) [22-23]:

$$
M B E=\sum_{1}^{N}\left(G_{i, m}-G_{i, c}\right) / N
$$

- Root Mean Square Error (RMSE): provides information on short-term performance by comparing the difference between estimated and measured values. The smaller the value, the better the model, given by the Eq. (8) [21, 22]:

$$
R M S E=\left[\sum_{1}^{N}\left(\mid\left(G_{i, m}-G_{i, c}\right)\right)^{2} / N\right]^{\frac{1}{2}}
$$

$m$ is the number of samples, $G_{i, m}$ and $G_{i, c}$ are the $i$-th measured and estimated values of global irradiation respectively.

\section{STUDIED SITES}

\subsection{Geographical coordinates}

For this study we have chosen seven sites: Algiers, Ain Bessem, Constantine, Oran, Djelfa, Mascara, and Tamanrasset. Measured values of solar irradiation have been provided from Metronome data source, in addition, they cover a considerable area of Algerian territory. Note that:

- Algiers is located in the Algerian north,

- Constantine is located in the Algerian east,

- Oran and Mascara are located in Algerian west,

- Djelfa and Ain Bessem are located in the middle south of Algeria, and

- Tamanrasset is situated in southernmost of Algeria.

Table 1. Geographical coordinates of the sites chosen

\begin{tabular}{cccc}
\hline Station & $\begin{array}{c}\text { Latitude } \\
(\mathbf{d e g})(\mathbf{N})\end{array}$ & Altitude(m) & $\begin{array}{c}\text { Longitude } \\
(\mathbf{d e g})\end{array}$ \\
\hline Oran & 35.38 & 99 & $0.37 \mathrm{~W}$ \\
Djelfa & 34.68 & 1126 & $3.25 \mathrm{E}$ \\
Ain Bessem & 36.31 & 629 & $3.67 \mathrm{E}$ \\
Tamanrasset & 22.47 & 1378 & $5.31 \mathrm{E}$ \\
Alger & 36,43 & 450 & $2.83 \mathrm{E}$ \\
Constantine & 36.17 & 687 & $6.37 \mathrm{E}$ \\
Mascara & 35.26 & 518 & $0.06 \mathrm{E}$ \\
\hline
\end{tabular}

In Table 1 is represented the geographical coordinates of studied sites.

\subsection{Metronome data}

Metronome is a complete meteorological reference including a catalog of meteorological data and calculation methods for solar applications and system design at any desired location in the world. It is based on more than 23 years of experience in the development of meteorological databases for energy applications. It brings together more than 20 measurement stations around the world. Table 2 presents the overall solar irradiance of studied sites.

Figure 1 shows the distribution of the average effective sunshine duration for a six-year period from the seven selected sites. It is more than 8 hours a day during the winter months and more than 12 hours a day during the months of June to July. The sites are therefore very favorable to the use of solar energy. 
Table 2. Summarizes the monthly average of measured values of global solar irradiation

\begin{tabular}{cccccccc}
\hline Month & Alger & Ain Bessem & $\begin{array}{c}\text { Const. } \\
\text { Measured values of }\end{array}$ & $\begin{array}{c}\text { Djelfa } \\
\text { global radiation solar Gm }\left(\text { M.J.m }^{-2}\right)\end{array}$ & $\begin{array}{c}\text { Mascara } \\
\text { (n) }\end{array}$ & \multicolumn{2}{c}{ Tamanrasset } \\
\hline January & 9.95 & 11.15 & 11.75 & 13.01 & 12.60 & 12.55 & 20.98 \\
February & 11.92 & 13.95 & 14.65 & 16.22 & 15.19 & 15.36 & 24.74 \\
March & 16.67 & 19.6 & 20.05 & 22.55 & 21.09 & 20.76 & 29.01 \\
April & 20.12 & 23.19 & 24.40 & 26.75 & 24.88 & 24.72 & 31.10 \\
May & 25.46 & 27.24 & 29.12 & 30.14 & 28.88 & 28.76 & 31.80 \\
June & 32.55 & 32.65 & 32.62 & 33.33 & 32.89 & 32.76 & 30.61 \\
July & 34.38 & 33.42 & 33.92 & 33.04 & 33.79 & 33.59 & 31.60 \\
August & 29.55 & 29.7 & 29.52 & 30.19 & 30.38 & 30.23 & 29.98 \\
September & 21.62 & 22.6 & 23.45 & 23.63 & 23.48 & 23.16 & 26.94 \\
October & 16.45 & 17.52 & 17.67 & 19.34 & 18.68 & 18.65 & 24.54 \\
November & 11.33 & 12.68 & 12.87 & 14.63 & 13.88 & 13.76 & 21.93 \\
December & 8.57 & 9.83 & 10.42 & 11.28 & 10.88 & 10.76 & 19.80 \\
\hline
\end{tabular}

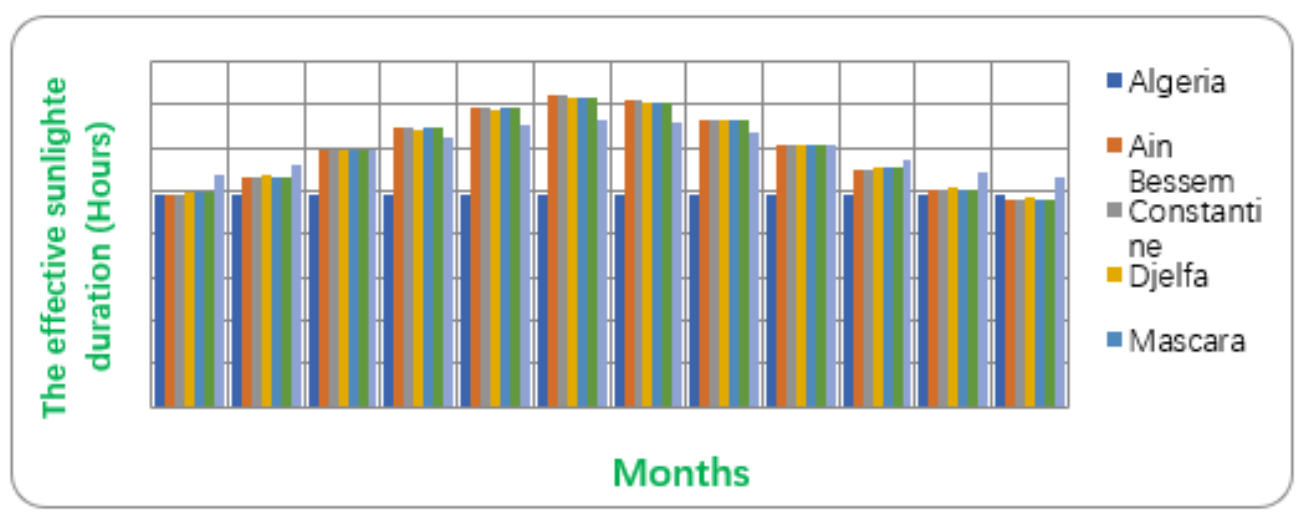

Figure 1. Distribution of the effective sunshine duration at the sites

\section{RESULTS DISCUSSIONS}

Using the different equations, the monthly average global solar irradiation was calculated and the different coefficients a and $\mathrm{b}$ were determined. Table 3 summarizes the expressions obtained for the different models as well as the statistical indicators of precision MAE, MBE and RMSE.

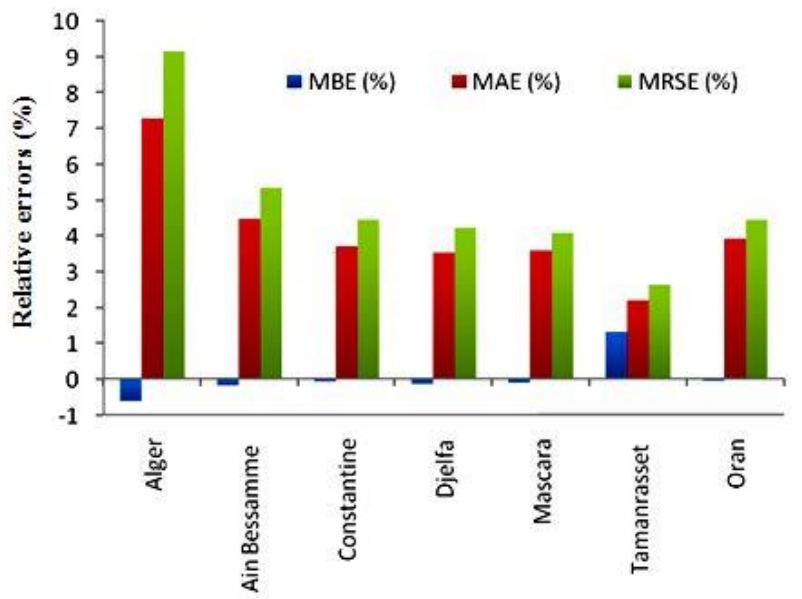

Figure 2. Relative errors between measured and calculated values by Angström model

Figure 2 shows the relative errors between the measured values and those calculated by the different models. We can observe that different methods provide good estimates of global irradiation. The maximum error was $9.137 \%$ obtained in Algiers by RMSE. However, the best results are obtained by the model with an MAE of $1.312 \%$ for Oran, while the great value of MAE was $5.041 \%$ for Constantine. The calculated results of the RMSE show that the best model is the linear model.

In Figure 3 is shown the estimated variation of global solar irradiation during six years. The maximum value of global solar irradiation estimated by Angström model is obtained in the months of June and July for the different sites:

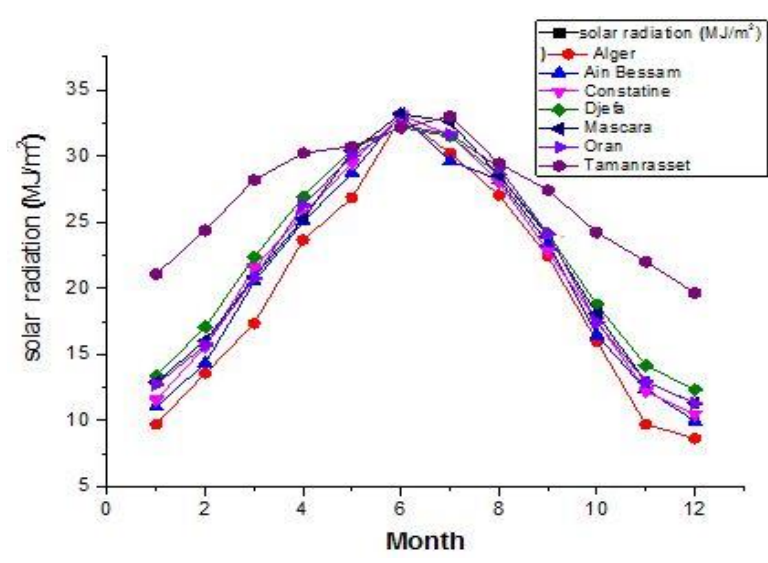

Figure 3. Estimated global solar irradiation

- Constantine: $33.13\left(\mathrm{MJ} . \mathrm{m}^{-2}\right)$,

- Djelfa: $32.18\left(\mathrm{MJ}_{\mathrm{m}}^{-2}\right)$,

- Mascara: $33.21\left(\mathrm{MJ}^{-2} \mathrm{~m}^{-2}\right)$,

- Oran: $32.33\left(\mathrm{MJ}^{-\mathrm{m}^{-2}}\right)$, and

- Tamanrasset: $33.02\left(\right.$ MJ.m $\left.^{-2}\right)$. 
Table 3. Developed models and values of MBE, MAE and RMSE

\begin{tabular}{ccccc}
\hline Site & Equation & MBE $(\%)$ & MAE $(\%)$ & RMSE $(\%)$ \\
\hline Algiers & $\mathrm{G} / \mathrm{G}_{0}=0.061+0.947\left(\mathrm{~S} / \mathrm{S}_{0}\right)$ & -0.622 & 7.260 & 9.130 \\
Ain Bessem & $\mathrm{G} / \mathrm{G}_{0}=0.447+0.427\left(\mathrm{~S} / \mathrm{S}_{0}\right)$ & -0.189 & 4.456 & 5.322 \\
Constantine & $\mathrm{G} / \mathrm{G}_{0}=0.448+0.381\left(\mathrm{~S} / \mathrm{S}_{0}\right)$ & -0.075 & 3.694 & 4.429 \\
Djelfa & $\mathrm{G} / \mathrm{G}_{0}=0.725+0.046\left(\mathrm{~S} / \mathrm{S}_{0}\right)$ & -0.147 & 3.511 & 4.203 \\
Mascara & $\mathrm{G} / \mathrm{G}_{0}=0.396+0.525\left(\mathrm{~S} / \mathrm{S}_{0}\right)$ & -0.111 & 3.571 & 4.066 \\
Oran & $\mathrm{G} / \mathrm{G}_{0}=0.47+0.392\left(\mathrm{~S} / \mathrm{S}_{0}\right)$ & -0.062 & 3.905 & 4.429 \\
Tamanrasset & $\mathrm{G} / \mathrm{G}_{0}=0.573+0.316\left(\mathrm{~S} / \mathrm{S}_{0}\right)$ & 0.130 & 2.188 & 2.623 \\
\hline
\end{tabular}

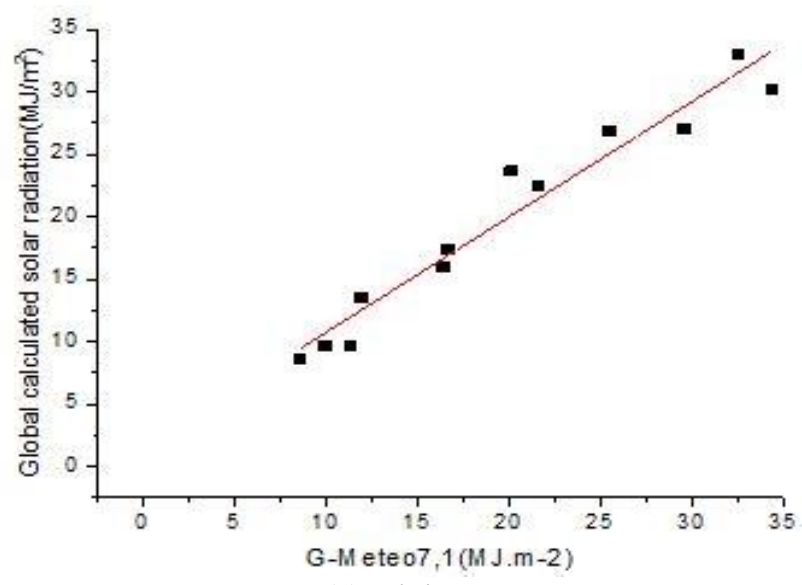

(a) Algiers

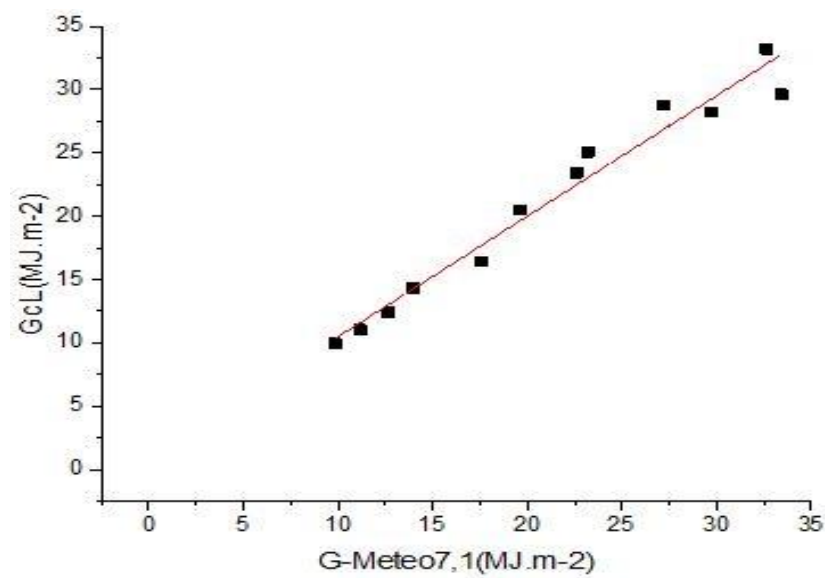

(b) Ain Bessem

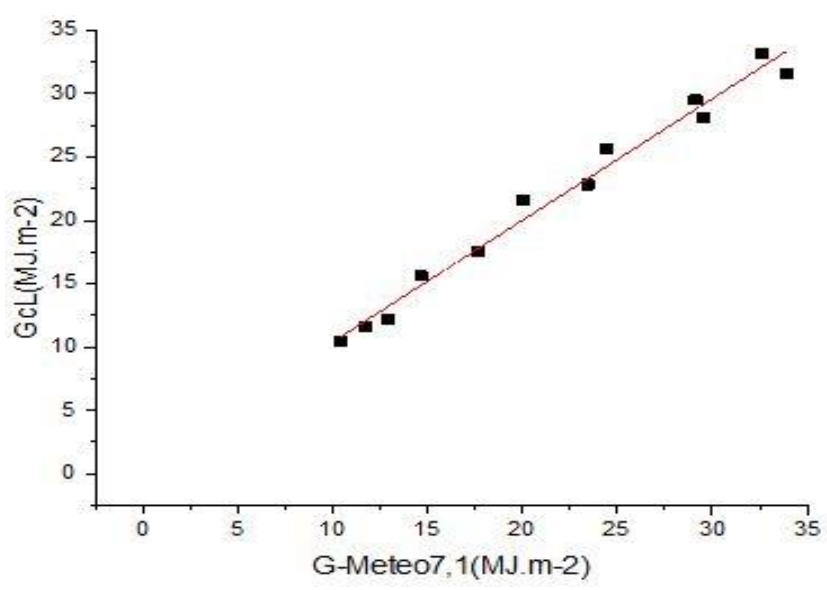

(c) Constatine

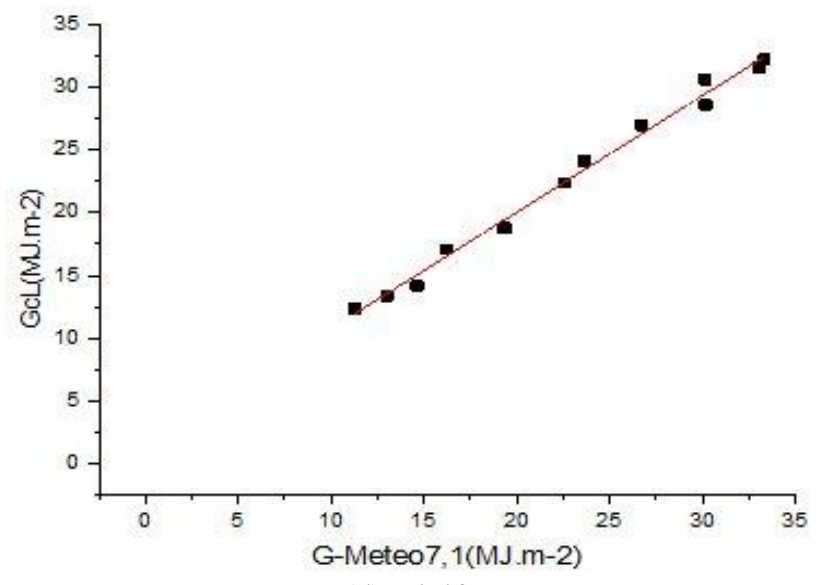

(d) Djelfa

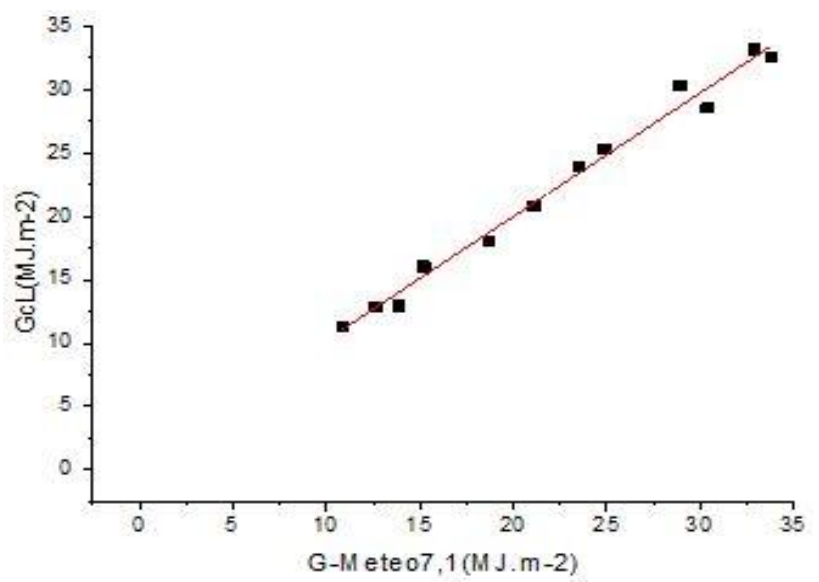

(e) Mascra

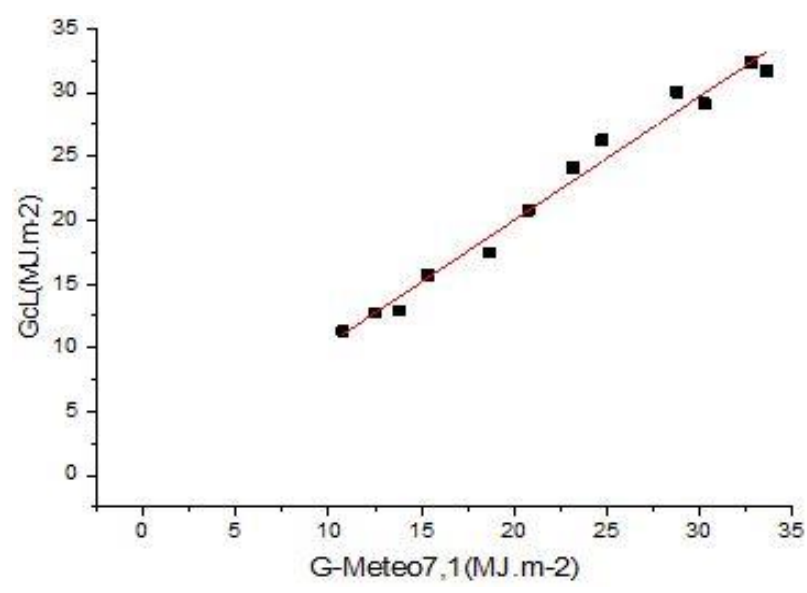

(f) Oran 


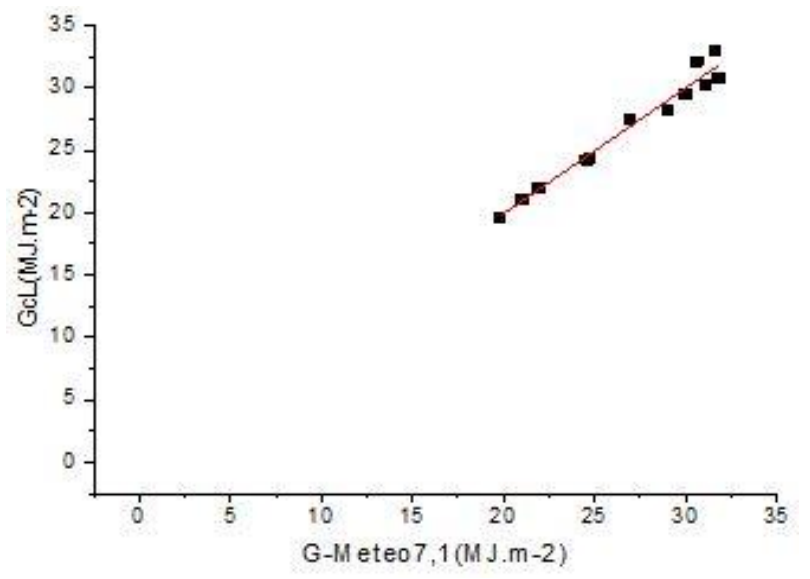

(g) Tammernsat

Figure 4. Comparison between measured and calculated global solar irradiation for deferent studied sites

To know the coefficients of connection between the measured and calculated values of each site, the results are presented in the Figure 4. Comparing the measured and calculated solar irradiation values of the seven regions, the order of the slope found is: Tamanrasset 1, Mascara and Oran 0.97, As Constantine and Ain Bassam 0.95. Algiers and Djelfa 0.92 .

\section{CONCLUSIONS}

The current subject is relevant and important for industrial applications. This recent analysis was reported in order to estimate the monthly global solar irradiation in the Algerian territory using the Angström model, for seven sites in Algeria, namely: Algiers, Ain Bessem, Constantine, Oran, Djelfa, Mascara and Tamanrasset. The present model was based on global solar irradiation in a horizontal surface as well as sunshine hours. To investigate the data obtained by the different sites, we calculated the following relative average algebraic differences: MAE, MBE and RMSE. Three main findings are summarized as follows:

- The different methods, i.e., MAE, MBE and RMSE, provided good estimates of global irradiation.

- The maximum error was approximately $9.137 \%$ obtained in Algiers by RMSE.

- The best results were obtained by the model with an MAE of $1.312 \%$ for Oran, while the great value of MAE was $5.041 \%$ for Constantine.

- The calculated results of the RMSE showed that the best model is the linear model.

- The maximum value of global solar irradiation estimated by Angström model is obtained in the months of June and July for the different sites investigated, i.e., 32.18, 32.33, 33.02, 33.13, and

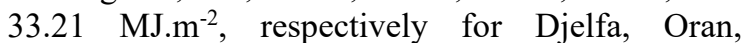
Tamanrasset, Constantine, and Mascara.

- A remarkable concordance between global solar irradiation obtained from G-Meteo 7.1 and the values measured by the Angström model using calculated estimates, especially in Tamanrasset site where the slope is of the order of 1 .

- Obtained estimates can be generalized on the whole Algerian territory to provide ease way for researchers to get solar irradiation. However, optimization efforts have to be made to reduce mean error. Future works can be made based on our estimates to study effect of temperature and climatic parameters on the model.

- This work aim is achieved providing a data generator (software).

The problem solved by the authors is potentially interesting for researchers and engineers working on solar collectors and aerospace industry.

\section{ACKNOWLEDGEMENT}

The authors would like to thank the General Directorate of Scientific Research and Technological Development (DGRSDT) of the Ministry of Higher Education and scientific research in Algeria, which sponsored this work.

\section{REFERENCES}

[1] Kamel, A., Amar, H.A., Aissa, C., Farida, C., Karim, K. (2014). Contribution for solar mapping in ALGERIA. In Progress in Sustainable Energy Technologies: Generating Renewable Energy, pp. 439-447. https://doi.org/10.1007/978-3-319-07896-0_26

[2] Ghodbane, M., Boussad, B. (2016). Estimating solar radiation according to semi empirical approach of Perrin de brichambaut: Application on several areas with different climate in Algeria. International Journal of Energetica, 1(1): 20-29.

[3] Yaiche, M.R., Bouhanik, A., Bekkouche, S.M.A., Benouaz, T. (2016). A new modelling approach intended to develop maps of annual solar irradiation and comparative study using satellite data of Algeria. Journal of Renewable and Sustainable Energy, 8(043702): 1-18. https://doi.org/10.1063/1.4958993

[4] Mondol, J., Yigzaw, G., Norton, B. (2008). Solar radiation modelling for the simulation of photovoltaic systems. Renewable Energy, 33(5): 1109-1120. https://doi.org/10.1016/j.renene.2007.06.005

[5] Ghodbane, M., Boussad, B. (2017). A parabolic trough solar collector as a solar system for heating water: a study based on numerical simulation. International Journal of Energetica, 2(2): 29-37.

[6] Rovense, F., Amelio, M., Ferraro, V., Scornaienchi, N.M., Rovense, F., Amelio, M., Ferraro, V., Scornaienchi, N.M. (2016). Analysis of a concentrating solar power tower operating with a closed joule brayton cycle and thermal storage. International Journal of Heat and Technology, 34(3): 485-490. https://doi.org/10.18280/ijht.340319

[7] Ma, C.C.Y., Iqbal, M. (1984). Statistical comparison of solar radiation correlations monthly average global and diffuse radiation on horizontal surfaces. Solar Energy, 33(2): $\quad$ 143-148. $\quad$ https://doi.org/10.1016/0038092X(84)90231-7

[8] Ganesh, G., Vijay Kumar, G., Babu, A.V., Rao, G.S., Tagore, Y.R. (2015). Performance analysis and MPPT control of a standalone hybrid power generation system. Journal of Electrical Engineering, 15(1): 334-343.

[9] Yilmaz, E., Cancino, B., Parra, W.R. (2007). Statistical analysis of solar radiation data. energy sources, part a: Recovery. Utilization and Environmental Effects, 29(15): 1371-1383. 
https://doi.org/10.1080/15567030701421505

[10] Jankovic, A., Lalic, B. (2014). Analysis of statistical methods for estimating solar radiation. Geographica Pannonica, 18(1):

$1-5$ https://doi.org/10.5937/GeoPan1401001J

[11] Khalil, S.A., Shaffie, A.M., Aly, H.A.S. (2018). Comparative and evaluate of empirical models for estimation global solar radiation in Al-Baha, KSA. Journal of Earth Science \& Climatic Change, 9(9): 1-10. https://doi.org/10.4172/2157-7617.1000492

[12] Wong, L.T., Chow, W.K. (2001). Solar radiation model. Applied Energy, 69(3): 191-224. https://doi.org/10.1016/S0306-2619(01)00012-5

[13] Swartman, R.K., Ogunlade, O. (2011). A statistical relationship between solar radiation, sunshine and relative humidity in the tropics. Atmosphere, 5(2): 25-34. https://doi.org/10.1080/00046973.1967.9676534

[14] Angstrom, A. (1924). Solar and terrestrial radiation. Report to the international commission for solar research on actinometric investigations of solar and atmospheric radiation. Quarterly Journal of Royal Meteorological Society, 50(21): 121-126. https://doi.org/10.1002/qj.49705021008

[15] Ampratwum, D.B., Dorvlo, A.S. (1999). Estimation of solar radiation from the number of sunshine hours. Applied Energy, 63(3): 161-167. https://doi.org/10.1016/S0306-2619(99)00025-2

[16] Darly, R.M. (2005). Solar radiation modelling and measurements for renewable energy applications: Data and model quality. Energy, 30(9): 1517-1531. https://doi.org/10.1016/j.energy.2004.04.034

[17] Yorukoglu, M., Celik, A.N. (2006). A critical review on the estimation of daily global solar radiation from sunshine duration. Energy Conversion and Management, 47(15-16):

2441-2450 https://doi.org/10.1016/j.enconman.2005.11.002

[18] De Souza, J.L., Nicácio, R.M., Moura, M.A.L. (2005). Global solar radiation measurements in Maceió, Brazil. Renewable Energy, 30(8): 1203-1220. https://doi.org/10.1016/j.renene.2004.09.013

[19] Duffie, J.A., Beckman, W.A. (1991). Solar engineering of thermal processes (pp. 770-772). New York: Wiley.

[20] Tiba, C., de Aguiar, R., Fraidenraich, N. (2005). Analysis of a new relationship between monthly global irradiation and sunshine hours from a database of Brazil. Renewable Energy, 30(6): 957-966. https://doi.org/10.1016/j.renene.2004.08.007

[21] Almorox, J., Hontoria, C., Benito, M. (2005). Statistical validation of daylength definitions for estimation of global solar radiation in Toledo, Spain. Energy Conversion and Management, 46(9-10): 1465-1471. https://doi.org/10.1016/j.enconman.2004.07.007

[22] Jacovides, C.P., Kontoyiannis, H. (1995). Statistical procedures for the evaluation of evapotranspiration computing models. Agricultural Water Management, 27(3-4): 365-371. https://doi.org/10.1016/03783774(95)01152-9

[23] Kumler, A., Xie, Y., Zhang, Y. (2019). A Physics-based Smart Persistence model for Intra-hour forecasting of solar radiation (PSPI) using GHI measurements and a cloud retrieval technique. Solar Energy, 177: 494-500. https://doi.org/10.1016/j.solener.2018.11.046

[24] Antonopoulos, V.Z., Papamichail, D.M., Aschonitis, V.G., Antonopoulos, A.V. (2019). Solar radiation estimation methods using ANN and empirical models. Computers and Electronics in Agriculture, 160: 160-167. https://doi.org/10.1016/j.compag.2019.03.022

[25] Liu, P., Tong, X., Zhang, J., Meng, P., Li, J., Zhang, J. (2019). Estimation of half-hourly diffuse solar radiation over a mixed plantation in north China. Renewable Energy, 149: 1360-1369. https://doi.org/10.1016/j.renene.2019.10.136

[26] Li, D.H., Chen, W., Li, S., Lou, S. (2019). Estimation of hourly global solar radiation using Multivariate Adaptive Regression Spline (MARS)-A case study of Hong Kong. Energy, 186: 115857. https://doi.org/10.1016/j.energy.2019.115857

[27] Srivastava, R., Tiwari, A.N., Giri, V.K. (2019). Solar radiation forecasting using MARS, CART, M5, and random forest model: A case study for India. Heliyon. 5(10): 02692. https://doi.org/10.1016/j.heliyon.2019.e02692

[28] Zhang, S., Li, X., She, J., Peng, X. (2019). Assimilating remote sensing data into GIS-based all sky solar radiation modeling for mountain terrain. Remote Sensing of Environment, 231 : 111239. https://doi.org/10.1016/j.rse.2019.111239

[29] Zang, H., Cheng, L., Ding, T., Cheung, K.W., Wang, M., Wei, Z., Sun, G. (2019). Application of functional deep belief network for estimating daily global solar radiation: A case study in China. Energy, 116502. https://doi.org/10.1016/j.energy.2019.116502

[30] Feng, Y., Gong, D., Zhang, Q., Jiang, S., Zhao, L., Cui, N. (2019). Evaluation of temperature-based machine learning and empirical models for predicting daily global solar radiation. Energy Conversion and Management, 198:

https://doi.org/10.1016/j.enconman.2019.111780

[31] Zaimi, M., El Achouby, H., Ibral, A., Assaid, E.M. (2019). Determining combined effects of solar radiation and panel junction temperature on all model-parameters to forecast peak power and photovoltaic yield of solar panel under non-standard conditions. Solar Energy, 191: 341-359. https://doi.org/10.1016/j.solener.2019.09.007

[32] Chen, Q., Ding, Q., Liu, X. (2019). Establishment and validation of a solar radiation model for a living wall system. Energy and Buildings, 195: 105-115. https://doi.org/10.1016/j.enbuild.2019.05.005

[33] Fan, J., Wang, X., Zhang, F., Ma, X., Wu, L. (2019). Predicting daily diffuse horizontal solar radiation in various climatic Rons of China using support vector machine and tree-based soft computing models with local and extrinsic climatic data. Journal of Cleaner Production, 119264. https://doi.org/10.1016/j.jclepro.2019.119264

[34] Chang, K., Zhang, Q. (2019). Improvement of the hourly global solar model and solar radiation for airconditioning design in China. Renewable Energy, 138: 1232-1238. https://doi.org/10.1016/j.renene.2019.02.069

[35] Zou, L., Wang, L., Li, J., Lu, Y., Gong, W., Niu, Y. (2019). Global surface solar radiation and photovoltaic power from coupled model intercomparison project phase 5 climate models. Journal of Cleaner Production, 224: 304-324. https://doi.org/10.1016/j.jclepro.2019.03.268

[36] Makade, R.G., Chakrabarti, S., Jamil, B. (2019). Prediction of global solar radiation using a single 
empirical model for diversified locations across India. Urban Climate, 29: 100492. https://doi.org/10.1016/j.uclim.2019.100492

[37] Manju, S., Sandeep, M. (2019). Prediction and performance assessment of global solar radiation in Indian cities: A comparison of satellite and surface measured data. Journal of Cleaner Production, 230: 116128. https://doi.org/10.1016/j.jclepro.2019.05.108

[38] Bendjamaa, I., Allaoui, T., Menni, Y., Chamkha, A.J., Lorenzini, E. (2019). Study and comparison between two receivers of parabolic trough collector. Mathematical Modelling of Engineering Problems, 6(3): 385-389. https://doi.org/10.18280/mmep.060309

\section{NOMENCLATURE}

the average monthly global irradiation
$\mathrm{G}_{0}$
$\mathrm{I}_{0}$

$\mathrm{N}$

$\mathrm{S}$

$\mathrm{S}_{0}$ measured on a horizontal plane $\left(\mathrm{MJ} \cdot \mathrm{m}^{-2} \cdot \mathrm{j}^{-1}\right)$. the monthly average global irradiation outside the atmosphere on a horizontal plane $\left(\mathrm{MJ} . \mathrm{m}^{-2} \cdot \mathrm{j}^{-1}\right)$.

the solar constant, is equal to $1367 \mathrm{Wm}^{-2}$.

the number of the day of the year from the first of January.

the duration of the effective sunshine.

the maximum duration of sunshine or duration of the day, its expression is given.

\section{Greek symbols}

$\Lambda \quad$ the latitude of the place, w: the hour angle.

$\Delta \quad$ the declination, it is given by the equation.

$\omega \quad$ the sunset hour angle. 